\title{
Mechanism and Design of Hanging Assembled Supporting Structure in the Roadway
}

\author{
Xiantang Zhang ${ }^{a}$, Yi Bai ${ }^{b}$, Hongmin Zhou ${ }^{c}$, Hongli Wang ${ }^{d}$ \\ Shandong Provincial Key Laboratory of Civil Engineering Disaster Prevention and Mitigation, \\ Shandong University of Science and Technology, Qingdao, Shandong 266590, China \\ azzxhtm@163.com, bcoolby2008@163.com, chongminzhou@163.com, dskdwhl@163.com
}

Keywords: Tunnel, Surrounding rock, Hanging, Assembled supporting

\begin{abstract}
The effect of the roadway supporting not only depends on the supporting force itself, but also depends on the surrounding rock, quantity of supporting placement, time and quality of setting up, and contacting points and surface in the surrounding rock. The classification, nature and failure mechanism of the surrounding rock are analyzed ,the author propose a new hanging and assembled supporting structure of the underground tunnel, and also analyzes its working mechanism and the reliability. This structure takes use of the interaction and common loading mechanism of the surrounding rock; it also offers a certain shrinkage value to achieve effective supporting effect. With pre-strength mortar bolt, resin bolt or advancing bolt together, we can more effectively prevent the surrounding rock loose to ensure the timeliness and effectiveness of the rock support.
\end{abstract}

\section{Introduction}

At present, the supporting in the underground roadway has many forms, for instance concrete support, shotcrete support, bolt support, net and shotcrete support. The common feature of this support is that the support system is a complete hard whole which is commonly known as the rigid support. When the tunnel pressure is big enough, this kind of rigid support will be crushed out of shape. The traditional solution is to increase the support thickness or laying mesh reinforcement to resist the pressure of underground roadway, so section size needs to be enlarged. It is a waste of supporting materials. But the effect of the roadway supporting not only depends on the supporting force itself, but also depends on the surrounding rock, quantity of supporting placement, time and quality of setting up, and contacting points and surface in the surrounding rock. Therefore, in order, we should take various measures to support the roadway effectively instead of considering bearing force only to achieve the best. The new hanging assembled supporting structure in the underground roadway can effectively resolve the problem of insufficient rigidity of the roadway support, and it offers a retractable stent support structure to achieve effective supporting effect.

\section{Factors affecting the stability of surrounding rock in underground works}

In general, underground engineering which is in the natural state is excavation and temporary or permanent construction in the underground. In order to study the state of surrounding rock and taking protective measures more conveniently, scholars from various countries have classified the surrounding rock intensively by the mechanical state of the surrounding rock, the nature and the structural characteristics, mining, tunneling and groundwater environment, construction factors[1]. The stability of surrounding rock in underground engineering is evaluated and monitored, to take appropriate supporting measures[2, 3]. Before the excavation, underground rock is in a state of natural balance. But the excavation breaks the stress equilibrium state, causing the stress redistribution, and also concerning the stability of surrounding rock. Factors affecting the stability of surrounding rock in underground works can be summarized as the load source factors, natural environment factors, and construction factors.

Load source factors.1) Self-weight stress. This kind of stress is weight of the overlying rock; it is 
linearly increased with the increasing depth of underground works.

2) Tectonic stress. It is the stress energy which is generated by tectonic movements in rockmass.

3) Loose rock pressure. It is the rock gravity on the roadway support which is caused by excavation and collapse.

4) Expansion stress. There are expansive clay minerals in the rock; the pressure is caused by the expansion, disintegration and increase in volume which is generated by weathering and water absorption.

5) Bearing pressure. The temporary additional bearing pressure caused by mining change over time, peak pressure can be several times higher than the static pressure, and can make the roadway generates larger stress and deformation.

Natural environment factors. 1) Groundwater. It includes the static pressure water, fissure water and construction water.

2) Weathering. After the excavation in underground, the surrounding rock will be in contact with air to produce weathering and disintegration, increasing the loose pressure of the surrounding rock; surrounding rock containing expansive clay minerals will expand after absorbing water.

3) Lithology. The surrounding rock in underground engineering tunnel is a natural load-bearing structure itself, the size of the carrying capacity is related to its strength. In general, the higher of the rock strength, the smaller of the damage of surrounding rock deformation, the easier of the roadway maintenance; low rock strength, high water absorption, development of bedding joints, containing expansive clay minerals, will weaken the stability and carrying capacity.

Construction factors. 1) Blasting tunneling. Blasting process, blast-hole layout, charge weight, charge structure is not controlled well, could easily lead to expand the scope of loose surrounding rock and reduce the self-carrying capacity[4].

2) Construction quality. Roadway and chamber in underground works are forming bad and uneven, there will be a stress concentration point, and it will increase the destructive effect of surrounding rock.

3) Support methods and scheme. The selection of roadway support methods and parameters is reasonable, they will be directly related to the stability of support and surrounding rock; performance of roadway support should adapt to the deformation characteristics. A rigid support or the retractable stent support is not suitable for unstable surrounding rock. For the roadway and chamber in loose rock should be promptly supported, it can limit rock deformation can avoid loose circle expand.

\section{Supporting methods of surrounding rock in underground tunnel}

Supporting principle. Discharging pressure, reinforcement, support in supporting works should be comprehensively arranged, support system, supporting structure and the construction process should be adapted to the mechanical state of the surrounding rock deformation to maximize the carrying capacity of the surrounding rock and the supporting capacity of protection system, in order to guarantee the stability of surrounding rock in underground works. At the same time, all above works should be combined with monitoring the changing. According to the state of the surrounding rock, we should timely adjust the supporting structure and parameters; choose the appropriate supporting structure and forms[5-7].

Supporting forms. 1) Traditional material. It includes stone and wooden bricks.

2) In-situ concrete supporting. It needs enough rigidity and section size to withstand the powerful loose ground pressure.

3) Retractable metal stents. It includes arched metal support and closed the metal stent; its shape also can be divided into circular, horseshoe-shaped, square ring.

4) Bolt-shotcrete supporting. It is the most common form of support, a popular form including anchor support, shotcrete support and composite form with other supporting structure supporting. It is widely used support for more than a thousand kilometers in mining engineering of China, because it is of advanced technology, economic, reliable quality, wide range of applications and a series of notable features. It can be used in the temporary support, permanent support, structural reinforcement, 
and falling repair works to withstand the static load or dynamic load in different rocks, different span, and different uses for underground works. In addition, it also can be combined with other forms of structure to form a composite support[4, 7].

5) Combined supporting. First, flexible bolting and shotcrete supporting should be adopted, then the in-situ concrete support or metal steel support. This is developed on the basis of the New Austrian Tunneling Method, the combined support technology has many forms.

6) Bolt-shotcrete and arc plate supporting. It is proposed by domestic scholars which is a development of combined support technology. The point is utilizing high-grade, high strength reinforced concrete arch board as rigid supporting to restrict the movement of the surrounding rock[6, 7].

\section{Mechanism and design of hanging assembled supporting structure in the roadway}

Research on hanging assembled supporting structure in the roadway. There are interaction and common loading between surrounding rock and supporting, it can effectively utilize bearing capability of the surrounding rock, and prevent the surrounding rock from loose damage, a feasible solution is to make the roadway support to provide some resistance to the surrounding rock, so that deformation of the surrounding rock is restricted to the roadway space under certain resistance; at the same time, supporting itself which suffers resistance of surrounding rock will generate a certain degree of deformation. The stress and deformation between support and surrounding rock are relevant, and change simultaneously.

Fig. 1 shows the new structure, it consists 2 support plate ,each plate is hanged in surrounding rock by bolt 1 , leaving expansion joints 4 between two adjacent sections, the width of expansion joints depends on the size of roadway deformation, the greater the deformation, the wider the joints, a flexible sealing strip 5 is pressed into the joints. The new support structure can be done promptly and rapidly to prevent the surrounding rock appear loose slump, especially with the use of pre-strength mortar anchor,resin bolt or advanced bolt, and to more effectively prevent the surrounding rock loose, ensure the timeliness and effectiveness of the support.

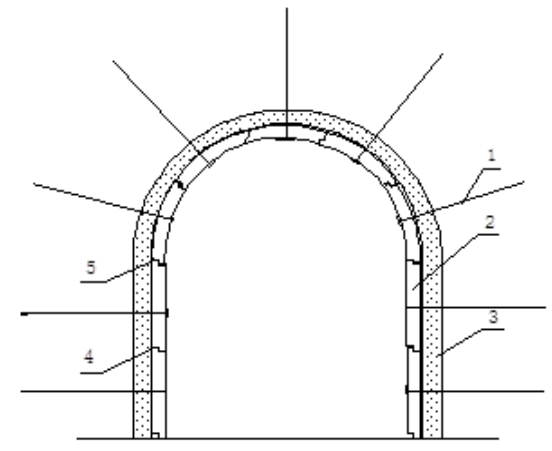

Fig. 1 Underground hanging assembled support structure

1-bolt; 2-support plate; 3-surrounding rock; 4- expansion joints; 5- flexible sealing strip

Analysis of the support structure from the mechanical point of view: one is from structural perspective, the support plate is seen as a beam or bearing arch, or as the bolt is fixed in the surrounding rock.The other one stress interaction between support and the surrounding rock.From their view,the support not only bear the pressure from surrounding rock, but also bring pressure to bear on surrounding rock to improve its pressure state.After supporting, strength of the surrounding rock is increased, and its bearing capability also improves. Both of them can play the role of the stability of surrounding rock.

Structure design of hanging assembled supporting structure plates. The plates can adopt rectangular reinforced concrete plates (Fig. 2),its arc should adapt to the roadway, there are 3 bolt holes in the longitudinal axis line for bolt hanging, its end face is like steps which is used for overlapping between plates; Within the plate there is structural steel to increase strength. The size of plates should be suitable for manual handling and installation, and $400 \times(600-800) \mathrm{mm}$ is better. The location of bolt holes depends on stability of surrounding rock, if the surrounding rock is stable you can leave a middle bolt hole for lifting; if not you can use both sides and middle ones for lifting. 


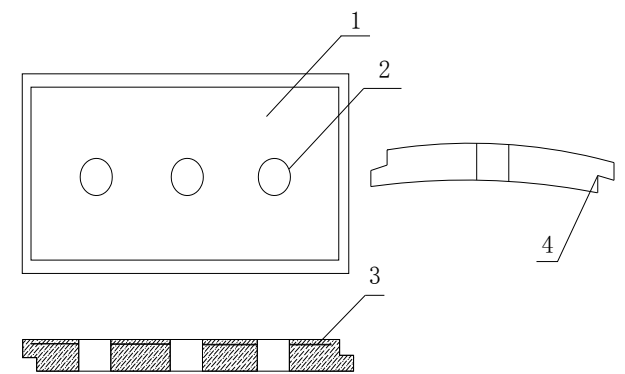

Fig. 2 Timbering plate structure sketch

1-Reinforced concrete plates; 2-bolt hole; 3- reinforcement; 4-end face of steps

The characteristics analysis of the assembled supporting structure.

1) Each support plate is hanged by bolt, taking use of the characteristics of bolt support which will be anchoring together with surrounding rock, and hanging support plate in the rock.

2) This kinds of plate structures use high strength concrete construction technology which are prefabricated on the ground and mechanized assembly in underground, composed of high strength reinforced concrete plate structure and construction is more convenient.

3) Leaving compression joints between the plates, when the surrounding rock has deformation, plates contract and release part of pressure, so that changing the rigid support to the flexible support which meet the principle of modern flexible supporting . Due to the release of pressure, the support pressure is reduced to avoid serious damage in supporting layer.

\section{Conclusion}

The new hanging assembled supporting structure utilize the interaction and common loading mechanism between the support and rock, and provides a retractable support structure to achieve effective rigid-flexible supporting, with the pre-strength anchor mortar, resin anchor or advanced bolt to effectively prevent the surrounding rock from loose,to ensure the timeliness and effectiveness of the rock support,it has good application prospects.

\section{Acknowledgment}

This work is financially supported by Shandong Province Higher Educational Science and Technology Program(J10LE11, J11LE10) and the Project of Qingdao Construction Technology Program (JK10-3), to which the author gratefully appreciates.

\section{References}

[1] Gancheng Xu, Hongcai Bai, Yingren Zheng: Support Structure in Underground Engineering (China Water Power Press, Beijing, 2002) (in Chinese)

[2] Yunliang Tan, Chuanxiao Liu: Stability Prediction and Control of Surrounding Rock in Roadway (China University of Mining and Technology Press, Xuzhou, 1999) (in Chinese)

[3] Jinquan, Jiang, Jisheng Han, Yongkui Shi: Structural Stability and Control Design of the Surrounding Rock in Roadway (China Coal Industry Publishing House, Beijing, 1999) (in Chinese)

[4] Xiantang Zhang, Xiaoming Zhang, Yuanping Sun, Xiaochen Zhou: Journal of Shandong University of Science and Technology(Natural Science), Vol.29 (2010), p. 48(in Chinese)

[5] Zuhe Wang, Mingyuan Wang, Jianping Wu: Quality Inspection of Bolting and Shotcrete Support Engineering (China Coal Industry Publishing House, Beijing, 1996) (in Chinese)

[6] Hongli Wang, Yubai Wang and Tao Chen: Industrial Construction (2005), p. 622(in Chinese)

[7] Qiang Fu and Xiaoyun Li: Mining Safety and Environmental protection (2007), p. 71(in Chinese) 